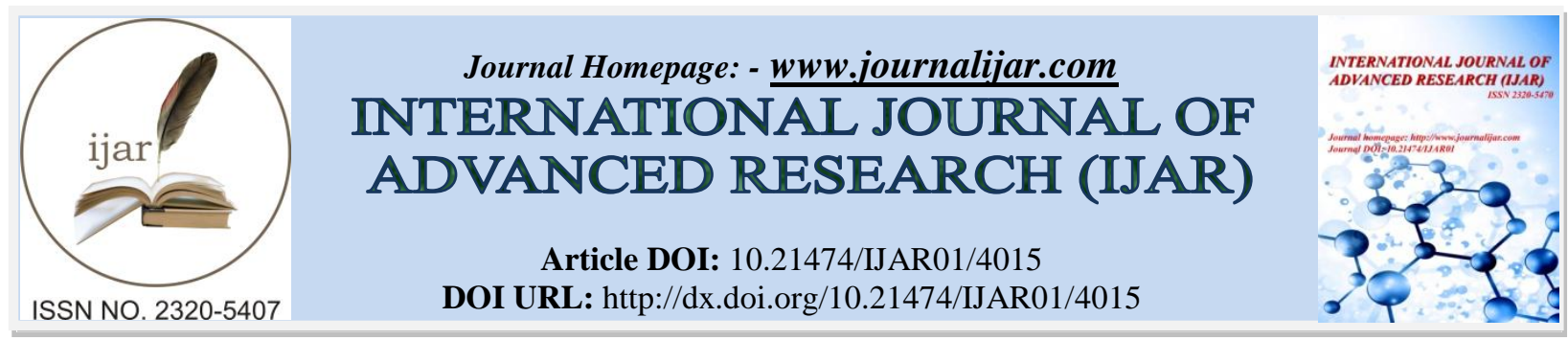

RESEARCH ARTICLE

\title{
EAR WAX REMOVAL: COMPARATIVE STUDY OF EFICACY AND ASSOCIATED COMPLICATIONS OF DISTILLED WATER, NORMAL SALINE AND 2\% PARA DICHLOROBENZENE.
}

\author{
Dr. Arshed Ali ${ }^{1}$, Dr. Asif Mahajan ${ }^{2}$ and Dr. Mohammad Ashraf ${ }^{3}$. \\ 1. Resident ENT, SMHS Hospital, Srinagar,J\&K,India. \\ 2. Resident ENT,SKIMS Medical College \& Hospital, Srinagar,J\&K,India. \\ 3. Assistant Professor,Deptt. Of Medicine, SMHS Hospital, Srinagar,J\&K,India.
}

\section{Manuscript Info}

Manuscript History

Received: 21 February 2017

Final Accepted: 15 March 2017

Published: April 2017

\begin{abstract}
Excessive ear wax can lead to symptoms such as hearing loss, tinnitus, itching, vertigo, and pain. There are many treatment options available for removal of impacted ear wax. The ceruminolytic effect of distilled water and $2 \%$ para-dichlorobenzene ear drops has been compared in this study. Aims \& Objective: (1) To compare the ceruminolytic effect of distilled water,normal saline and commercially available $2 \%$ paradichlorobenzene ear drops; (2) To observe and analyze the complications during the usage of these agents. Materials and Methods: A total of 100 patients who attended the ENT OPD and were diagnosed to have impacted ear wax completely occluding the ear canal were included in the study. They were divided into three groups Group A,Group B and Group C. Group A patients were advised to use distilled water as ear drops, Group B patients were advised to use normal saline as ear drops and Group $\mathrm{C}$ were adcised to use comercailly available $2 \%$ para-dichlorobenzene ear drops. Results: From the results it is clear that using distilled water and normal saline as ear drops does lead to significantly more complications and pain during removal than $2 \%$ Para dichlorobenzene ear drops. The results also point that removal becomes significantly easier when distilled water and normal saline is used compared to $2 \%$ Para dichlorobenzene. No statistically significant difference has been noted in the number of attempts required to achieve complete removal between the two groups. Complications included perforation, canal lacerations, and failure of wax removal. The removal of occlusive wax improved hearing by a mean of $5 \mathrm{~dB}$ over the frequencies analysed. Conclusion: The results indicate that the usage of distilled water and normal saline on a regular basis as a ceruminolytic ear drop cannot be recommended.
\end{abstract}

Copy Right, IJAR, 2017,. All rights reserved.

\section{Introduction:-}

Cerumen or ear wax is a mixture of the glandular secretions from the lateral third of the ear canal and exfoliated squamous epithelium. It lubricates the ear canal, acts as a trap for dust, hair and insects. Normally cerumen is eliminated or expelled by self-cleansing mechanism which causes it to migrate out of the ear canal assisted by jaw movements ${ }^{[1]}$ 
Cerumen or wax impaction is defined as accumulation of cerumen that causes symptoms, prevents a needed assessment of ear canal/tympanic membrane or audiovestibular system or both. Symptoms associated with cerumen impaction vary from simple itching to hearing loss to tinnitus and vertigo ${ }^{[2]}$ Impacted cerumen is a major cause of primary care consultation and common co-morbidity in ENT patients ${ }^{[3]}$ and people with mental retardation ${ }^{[4]}$. Ear wax removal is the otolaryngological procedure most commonly performed by Otolaryngologists.Wax may cause tinnitus or otalgia and removal may be required to allow adequate otoscopic examination, but many patients with a sensorineural hearing loss request repeated ear syringings in the mistaken belief that these will restore auditory acuity. Potential complications include perforation, otitis externa, vertigo, and cardiac arrest ${ }^{[5]}$ The optimal and effective treatment of cerumen is time consuming in many cases, delays the required assessment in some and moreover has remained a controversial subject for many centuries.

There are many treatment options available for cerumen impaction including observation, ceruminolytic agents, irrigation or manual removal other than irrigation and also combination of ceruminolytic agents with either irrigation or manual removal. ${ }^{[2]}$

\section{Materials and Methods:-}

This study was performed in the Department of ENT and Head \& Neck Surgery, GovernmentMedical College Srinagar, J \&K. A total of 100 patients who attended the ENT OPD between April 2016 to November 2016 and diagnosed to have impacted ear wax completely occluding the ear canal were included in the study. The patients were in the age 12 yr to 70 years of both sexes. An informed consent was obtained from the patients in a prescribed form at the time of inclusion in the study. A total of 134 ears were divided into three groups - Group A- 44 ears, Group B- 50 ears and Group C-40 ears. The patients were randomized and not the ears because this was more practical. Randomization was done based on the OPD number of the patients.

\section{Exclusion Criteria.}

All patients with previous history of ear discharge or any otological surgery. Also patients who had pain, otitis externa or otomycosis at presentation

\section{Methodology:-}

Method of administering the ear drop was same in all three groups. They were advised to lie with the affected ear top most and instil 4 drops and exert inward pressure over the tragus 8-10 times. They were advised not to use cotton plugs and to remain in that position for 5 minutes. If the patient had bilateral wax he/she was advised to follow the same procedure for the other ear after 30 minutes. They were advised to use the ear drops 4 times every day for 5 days and return on the 6th day for wax removal. Each patient was explained about the possibility of any complication developing during the usage of these medications and was asked to report in case of any such occurrence. They were treated fully for the complications also. During review visit each patient was assessed for any complication which was not reported earlier and recorded accordingly.

Syringing was used as the main method of wax removal and in some cases instrumentation was required in addition to Syringing. End point was complete removal of wax allowing full visualization of tympanic membrane. If this was not achieved during first review (6th day), then patient was instructed to continue same medication in the same fashion for another 5 days and review again for removal and this procedure followed till the end point was achieved. During removal presence of pain was noted and recorded. The number of attempts required for complete removal in each ear was also recorded.

\section{Results:-}

In the present study patients were in the age group 12-70yrs. Maximum number of patients was in 12-25 years of age in the three groups \% in Distilled water group (Group A) and \% in 2\% Para dichlorobenzene group (Group B).

The age distribution of subjects selected for the present study is shown in Figure 1. where they had maximum number of patients in the age group 12-25 years. Also a study on age related changes in ear wax secretion by Jacobsen observed that there is reduction in sebum production in males and females almost to the same degree as age advances ${ }^{[6]}$

There were 21 males and 16 females in Group A, 23 males and 15 females in Group B, 24 male and 11 females in Group C (Figure 2). Similar finding of more incidence of ear wax in male patients has been noted by Stone and 
Falghum in their study ${ }^{[7] .}$ This has been attributed to the larger and coarser hairs in the external auditory canal of males. However many studies ${ }^{[8,9,10]}$ did not find any significant difference in the sex incidence of cerumen impaction.

In Group A there were 37 patients with right ear 18 cerumen impaction, 12 with left ear cerumen impaction and 7 patients with bilateral wax impaction. In Group B there were 38 patients with right ear 14 wax impaction, 12 with left ear wax impaction and 12 had bilateral impaction and In Group C there were 35 patients with right ear 16 cerumen impaction, 14 with left ear cerumen impaction and 5 patients with bilateral wax impaction.

\section{Specific Parameters:-}

First specific parameter studied was development of any complication during usage of the medication. The complications encountered were increase in ear block, otitis externa and otomycosis. About 8 patients in Group A, 7 patients in Group B and 2 Patients in Group C developed complications. The details are given in Table 1. Study showed that there is a significant increase in the incidence of complications while using distilled water as ear drops and normal saline. While there is less complication with $2 \%$ para-dichlorobenzene ear drops. $(\mathrm{p}<0.05)$.

The next parameter studied was ease of removal. It was considered easy removal if only syringing was required and difficult if instrumentation was required in addition to syringing (score 2). It was observed that after using distilled water and normal saline it was easier to remove wax using only syringing. The results have been tabulated in Table 2. These results were analyzed to see if this difference is statistically significant and it was observed that there is a statistically significant difference in the ease of removal between the three groups $(\mathrm{p}<0.05)$.

The third parameter studied was pain during removal. There were 7 patients who experienced pain in one of the ears during removal in Group A 5 patients and Group B 6 patients, whereas no patient experienced pain in Group C. This difference was found to be statistically significant $(\mathrm{p}<0.05)$.

The fourth parameter that has been analyzed in the efficacy was number of attempts at complete removal. The results are shown in Table 3. There was only one patient who required a total of 3 attempts for complete removal in Group $\mathrm{C}$ whereas maximum attempts required in all other ears were either 1 or 2 in all three groups. However analysis of these results did not show any statistically significant difference between the three groups $(p>0.05)$.

Table 1:- Complications

\begin{tabular}{|l|l|l|l|}
\hline COMPLICATIONS & GROUP A $(n=44$ EARS $)$ & GROUP B $(n=50$ EARS $)$ & GROUP C $(n=40$ EARS $)$ \\
\hline INCREASE EAR BLOCK & 1 EAR & 1 EAR & 1 EAR \\
\hline OTOTIS EXTERNA & 5 EARS & 4 EARS & 1 EAR \\
\hline OTOMYCOSIS & 2 EARS & 2 EARS & NIL \\
\hline
\end{tabular}

Table 2:- Ease Of Removal

\begin{tabular}{|l|l|l|l|l|l|}
\hline EASE OF REMOVAL & $\begin{array}{l}\text { GROUP A }(\mathrm{n}=44 \\
\text { EARS })\end{array}$ & $\begin{array}{l}\text { GROUP } \\
\text { EARS })\end{array}$ & B $(\mathrm{n}=50$ & $\begin{array}{l}\text { GROUP } \\
\text { EARS })\end{array}$ \\
\hline ONLY SYRINGING & 28 EARS & & 36 EARS & & 12 EARS \\
\hline SYRINGING+INSTRUMATION & 16 EARS & & 14 EARS & & 28 EARS \\
\hline
\end{tabular}

Table 3:- Attempts At Complete Removal

\begin{tabular}{|l|l|l|l|}
\hline ATTEMPTS & GROUP A $(\mathrm{n}=44$ EARS $)$ & GROUP B $(\mathrm{n}=50$ EARS $)$ & GROUP C $(\mathrm{n}=40$ EARS $)$ \\
\hline ONE & 39 & 42 & 32 \\
\hline TWO & 5 & 8 & 7 \\
\hline THREE & NIL & NIL & 01 \\
\hline
\end{tabular}

Age \& Sex Wise Distribution Of Patients In Group A,Group B And Group C

\begin{tabular}{|l|l|l|l|l|l|l|}
\hline & \multicolumn{2}{l|}{ GROUP A } & GROUP B & \multicolumn{2}{l|}{ GROUP C } \\
\hline AGE GROUPS & MALE & FEMALE & MALE & FEMALE & MALE & FEMALE \\
\hline $12-25$ YRS & 13 & 10 & 16 & 8 & 17 & 5 \\
\hline $25-40$ YRS & 4 & 3 & 4 & 5 & 5 & 3 \\
\hline $40-55$ YRS & 3 & 2 & 2 & 1 & 1 & 2 \\
\hline
\end{tabular}




\begin{tabular}{|l|l|l|l|l|l|l|}
\hline $55-70$ YRS & 1 & 1 & 1 & 1 & 1 & 1 \\
\hline
\end{tabular}

No Of The Patients With Different Sides Of Ear

\begin{tabular}{|l|l|l|l|}
\hline & RIGHT & LEFT & BILATERAL \\
\hline GROUP A & 18 & 12 & 7 \\
\hline GROUP B & 14 & 12 & 12 \\
\hline GROUP C & 16 & 14 & 5 \\
\hline
\end{tabular}

\section{Discussion:-}

From the results it is clear that using distilled water and normal saline as ear drops does lead to significantly more complications than 2\% Para-dichlorobenzene ear drops. However the results also point that removal becomes significantly easier when distilled water and normal saline are used compared to $2 \%$ Para-dichlorobenzene. Chosen method of choice for removal in all three groups was syringing. This has allowed a comparison of the exclusive effect of distilled water and normal saline against that of 2\% Para dichlorobenzene. Water has been shown to have a ceruminolytic action whereas $2 \%$ Para-dichlorobenzene is a wax softening agent and so the disintegration of wax after using water may be more effective.

There is also significantly more pain during removal in patients who used distilled water and normal saline. The reason for this may be that when water and normal saline collects in the ear canal especially when trapped by wax, the skin can become soggy and this may render the area more sensitive to pain. Though this is a theoretical possibility, the post removal appearance of canal skin has not been included in this study and hence is difficult to conclude. The other reason may be due to more patients with complications like otitis externa and otomycosis in Group A and Group B.

Considering all these factors, though distilled water and normal saline is as effective as $2 \%$ Paradichlorobenzene ear drops and is in fact a better ceruminolytic facilitating easier removal, regular usage of this as ear drops cannot be recommended based on this study. At the same time, further detailed study will be needed with respect to each and every complication seen during this study for a better understanding of their actual clinical impact.

Our results show a $5 \mathrm{~dB}$ increase in auditory acuity for the frequencies analysed after the syringing of occlusive wax. This is a small improvement but may be sufficient to allow a patient whose hearing thresholds border on the requirement for a hearing aid to be able to function socially without auditory amplification.

\section{Conclusion:-}

Distilled water and normal saline used as ear drops is as effective as $2 \%$ Para-dichlorobenzene and in fact makes removal of impacted wax easier. However since the complication rate while using distilled water and normal saline are more compared to $2 \%$ Para-dichlorobenzene, the usage of distilled water and normal saline on a regular basis as a ceruminolytic ear drop canot be recommended.

\section{References:-}

1. Alberti PW. Epithelial migration on the tympanic membrane. J Laryngol Otol 1964;78:808-30.

2. Roland PS, Smith TL, Schwartz SR, Rosenfeld RM, Ballachanda B, Earll JM, et al. Clinical practice guideline: cerumen impaction. Otolaryngol Head Neck Surg. 2008;139:S1-S21.

3. Freeman RB. Impacted cerumen: how to safely remove earwax in an office visit. Geriatrics 1995;50:52-3.

4. Crandell CC, Roeser RJ. Incidence of excessive impacted cerumen in individuals with mental retardation: A longitudinal investigation. Am J Ment Retard 1993;97:568-74.

5. Prasad KS. Cardiac depression on syringing the ear. 7 Laryngol Otol 1984;98: 1013.

6. Jacobsen E, Billings JK, Frantz RA, Kinney CK, Stewart ME, Downing DT. Age related changes in sebaceous wax secretion in men and women. J Invest Dermatol 1985;85:483-5.

7. Stone M, Falghum RS. Bacteriological activity of wet cerumen. Ann Otol Rhinol Laryngol 1984;93:183-6.

8. Nair P, Golhar S, Baisakhiya N, Deshmuk PT. A Comparative study of ceruminolytic agents. Ind J Otolaryngol Head and Neck Surg 2009; 61:185-92.

9. Jacobsen E, Billings JK, Frantz RA, Kinney CK, Stewart ME, Downing DT. Age related changes in sebaceous wax secretion in men and women. J Invest Dermatol 1985;85:483-5.

10. Cipriani C, Taborelli G, Gaddia G, Melagrana A, Rebora A. Production rate and composition of cerumen-Influence of sex and season. Laryngoscope 1990;100:275-6. 